\title{
Monitoring Multi-Parameters of a Motor Using GSM
}

\author{
Y. N. Ravindra ${ }^{1}$, R. B. Konda ${ }^{2}$
}

${ }^{1}$ Head Department of Electronics, Smt. V. G. Degree College for Women, Kalaburagi, Karnataka, India ${ }^{2}$ Assistant Professor, Department of Electronics, Smt. V. G. Degree College for Women, Kalaburagi, Karnataka, India

\begin{abstract}
Now-a-days wireless and mobile communication is the major tool that can be used to provide the information to the operator for their supervisory. The mobile communication technology in the recent years has been extensively used in different form in different application areas. In this paper, the proposed scheme uses Global System for Mobile (GSM) modem along with the microcontroller which is interfaced with analog unit to display the motor performance parameters like temperature, speed, voltage, current, direction and status on Liquid Crystal Display (LCD). The same data can be acquired remotely through Short Message Service (SMS) from the user mobile handset by dialling the mobile number of SIM of GSM modem. The system is capable of monitoring the motor by receiving message from an authorized mobile number. Microcontroller is the heart of our system, which controls the overall operation of our system. System is always alert for receiving SMS from valid number and that message can be displayed on the LCD. This add-on unit monitors parameters of any motor (AC or DC). A proto-type lab model is set up and is working satisfactorily. The monitoring of the system is realized in real time.
\end{abstract}

Keywords : GSM modem, microcontroller, sensors, signal conditioner, LCD

\section{INTRODUCTION}

In the twenty first century, there is revolution of the sensor networks which have also come up with various applications like surveillance, traffic control, agricultural application, home automation and industrial process control. In today's world the need of the hour is atomization - remote monitoring, quick data acquisition and failure analysis and brings efficiency in asset management.

In the backdrop of above as we know that it is not possible, rather difficult, to keep track of the motor by days long manual observation. On the other side, modern civilization is advancing at very faster pace with the adoption of wireless technology. The convergence of wireless technology and the embedded technology with the different transducers makes these supervisory systems more reliable, much efficient as well as cost effective one. Keeping this in mind, the present approach has been made to apply the advantages of wireless communication and embedded technology towards monitoring the multiparameters of a motor using GSM. This Proposed work is a very good example of embedded system as all its operations are controlled by intelligent software inside the microcontroller. The aim of this work is to monitor the following parameters of the motor:
1. Temperature
2. Speed
3. Voltage 


\section{Current \\ 5. Direction \\ 6. Status}

For this purpose user can use any type of Mobile. This way it overcomes the limited range of infrared and radio remote controls. Using the convenience of SMS, this unit lets you remotely monitor the motor parameters, all of which can be pre-programmed into the controller.

\section{SYSTEM IMPLEMENTATION}

The block schematic of the proposed scheme is as shown in the Fig. 1. The heart of the system is the Microcontroller AT mega - 16 which is interfaced to the analog signal conditioner unit. This unit consists of sensors and signal conditioner for each parameter to be measured. The temperature sensor IC LM35 is used for sensing the motor temperature. The analog voltage from LM 35 is made compatible to microcontroller by using signal conditioner unit. This unit consist of scaling amplifier by which calibrated DC output proportional to temperature is given to analog port PA0 of the microcontroller, which converts it in to digital and displays on LCD.

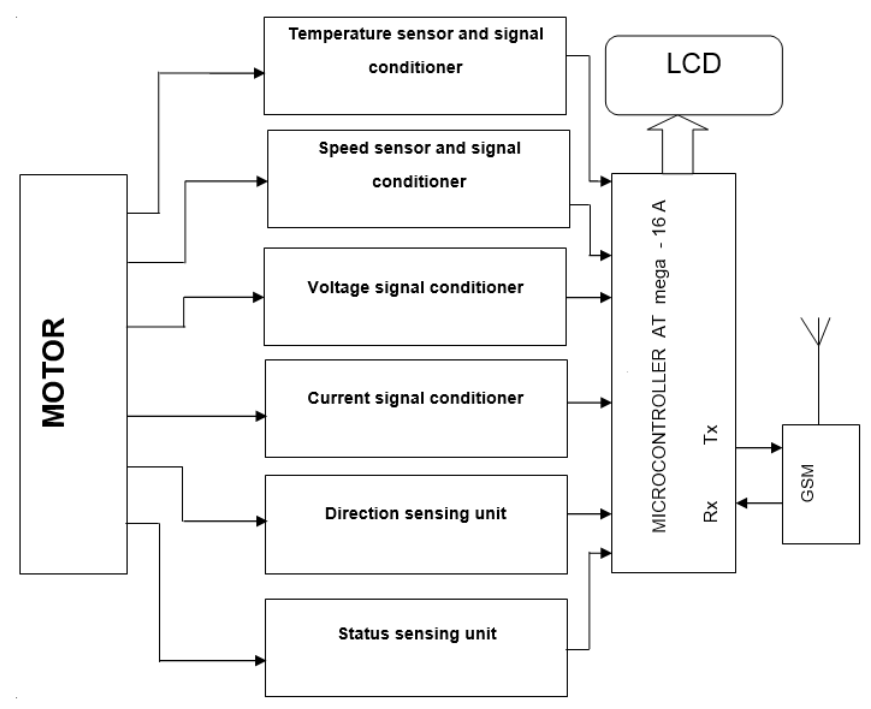

Figure 1: Block Diagram of proposed system.

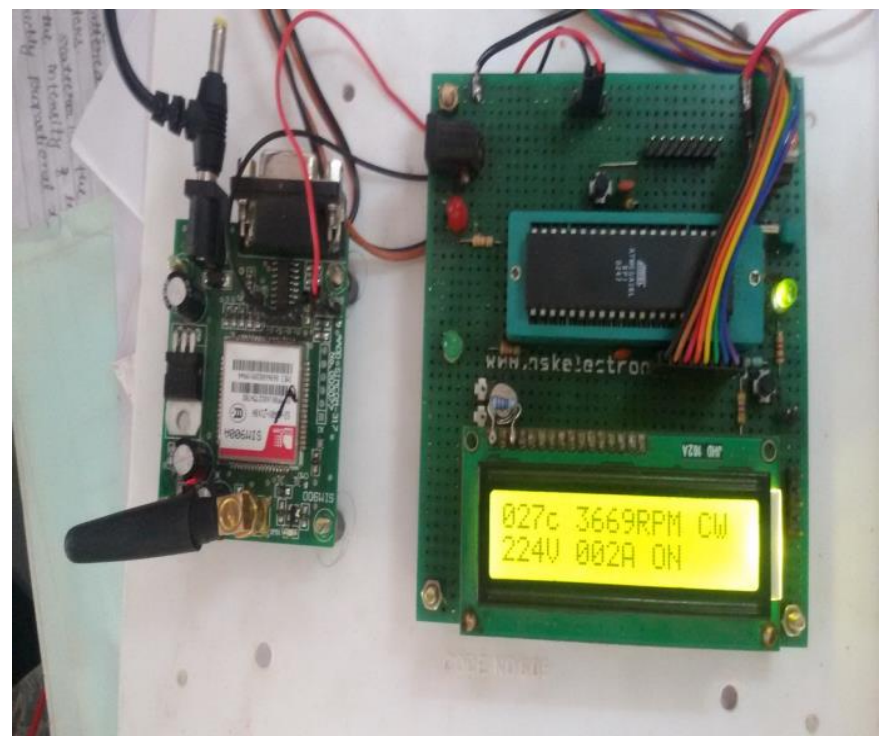

Figure 2: Prototype Unit of GSM based Add-On Unit

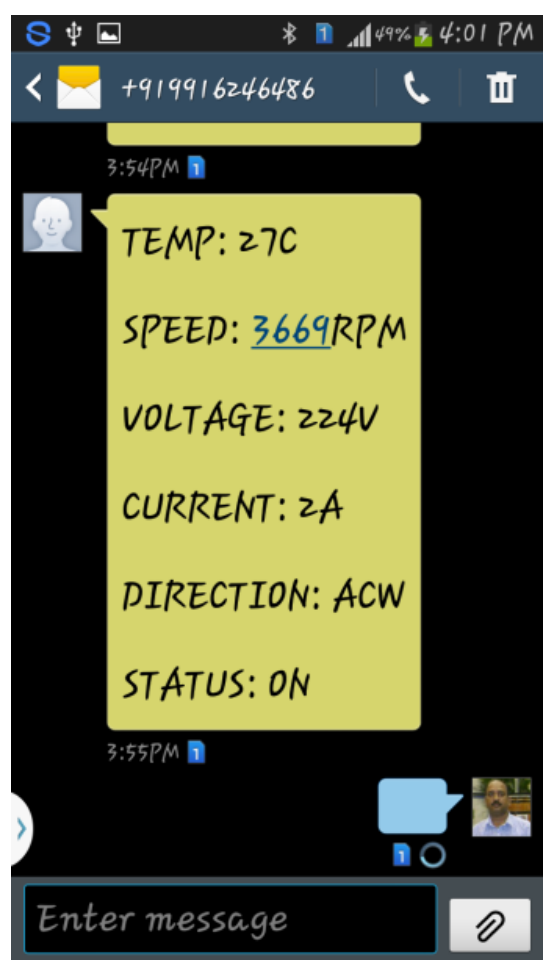

Figure 3: SMS display

'Texting', as its also known, is a fast and convenient way of communicating. In fact, SMS has taken on a life of its own, spawning a whole new shorthand language that's rapidly growing. Many industries have been quick to make use of this technology, with millions of handsets currently in use. As new models with "must have" features hit the market, older 
models become virtually worthless and if not recycled, end up in landfill. With this in mind, in the proposed work we have designed to work with SIM900A GSM modem with simcom technology.

The speed sensor uses inductive proximity sensor, which provides pulses corresponding to the speed of the motor. The frequency of the pulses depends on the speed of the motor. This frequency is converted into analog voltage by frequency to voltage converter IC LM 331. This analog voltage fed to signal conditioning unit for providing calibrated DC output proportional to the speed of the motor. So, this signal conditioning unit provides maximum $5 \mathrm{~V}$ corresponding to a motor speed of $5000 \mathrm{rpm}$. Similarly voltage and current of the motor are sensed by potential and current transformer, rectifier, filter and scaling unit which are made to provide $5 \mathrm{~V}$ when line voltage is around $500 \mathrm{~V}$ and $5 \mathrm{~V}$ when maximum current drawing by the motor is around 50A. These analog voltages are fed to corresponding pins of the analog port of the microcontroller to digitize the analog voltage and display on LCD as 500V and 50A.

A separate logic unit is designed for sensing Direction and Status of the motor that will provide 0 logic for clockwise and logic 1 for anti-clockwise, for logic 0 the status of the motor is OFF and logic 1 for ON. These logic levels are interfaced to microcontroller to display direction as CW/ACW and status as ON or OFF on LCD as shown in the Fig. 2. and Fig.3 shows SMS display on user mobile.

Finally, serial interfacing of GSM modem with Tx and $\mathrm{Rx}$ pins of microcontroller for providing SMS data remotely on dialling the SIM number of the GSM modem is incorporated. A DC power supply for digital unit is provided by $5 \mathrm{~V}$ DC and analog unit will be sourced by the $+/-12 \mathrm{~V}$ DC.
The prototype system is tested with temperature sensor LM35, inductive proximity speed sensor, potential and current transformer for voltage and current measurement. The unit is tested with universal motor 230V, 1/16 H.P, 8000rpm.

\section{CONCLUSION}

The approach discussed in the paper has achieved the target of monitoring the motor parameters. The proposed unit provides many applications such as industrial applications; one can monitor the performance parameters of a motor from a long distance and can be used by everyone with the knowledge of text message. Since the unit is network dependent so network congestion can reduce the reliability of the system and this unit monitors the parameters but do not control it. Hence we can conclude that the required goals and objectives of GSM based monitoring multi-parameters of motors have been achieved.

\section{REFERENCES}

[1] R. Teymourzadeh, S. Ahmed, K.W.Chan \& M. V. Hoong, "In systems, process control (ICSPC)", 2013 IEEE Conference on Dec. 2013, pp. 306-309.

[2] Muhammad Ali Mazadi and Janice Gillispie Mazidi, "The 8051 Microcontroller \& Embedded system using assembly and C", Pearson Education, September 2007, Second Edition.

[3] Kung, P., Wang, L. and Comanici, M. I., "Stator end-winding vibration and temperature rise monitoring," Proc. IEEE Electric Insulation Conference, 10-14 (2014).

[4] Fabian, M., Borg Bartolo, J., Ams, M., Gerada, C., Sun, T. and Grattan, K. T. V., "Vibration measurement of electrical machines using integrated fibre Bragg gratings," Proc. 24th International Conference on Optical Fiber Sensors, Vol. 9634, 2015. 
[5] "Wireless Telecommunication Systems and Networks", Mullet: Thomson Learning 2006.

[6] H. Elkamchouchi, Ahmed Elshafee, "Design and prototype implementation of SMS based home automation system" 2012 IEEE International Conference on Electronics Design, Systems and Applications (ICEDSA), 5-6 Nov. 2012, pp. 162167.

\section{Cite this article as :}

Y. N. Ravindra, R. B. Konda, "Monitoring MultiParameters of a Motor Using GSM", International Journal of Scientific Research in Science and Technology (IJSRST), Online ISSN : 2395-602X, Print ISSN : 2395-6011, Volume 7 Issue 3, pp. 01-04, MayJune 2020. Available at doi : https://doi.org/10.32628/IJSRST207295 Journal URL : http://ijsrst.com/IJSRST207295 